Siti masruroh

Vol 3 No 2

ISSN : 2541-6995

E ISSN : 2580-5517

\title{
URGENSI PEMBINAAN KEMAMPUAN BACA AL-QURAN TERHADAP MAHASISWA PERGURUAN TINGGI UMUM MENGHADAPI TANTANGAN REVOLUSI INDUSTRI 4.0
}

\author{
Siti masruroh \\ Universitas Buana Perjuangan Karawang \\ Email: Siti.masruroh@ubpkarawang.ac.id
}

Abstrak

Kemajuan teknologi informasi telah banyak merubah pola dalam segala sendi kehidupan, begitupun pembiasaan baca Al-Qur'an pelan-pelan sudah mulai ditinggalkan, oleh generasi muda saat ini memiliki kemampuan mengakses informasi lebih cepat yang berakibat berpengaruh terhadap pola kehidupan. Kemajuan teknologi informasi telah merubah kebiasaan dan pola hidup. Esensi revolusi industry 4.0 adalah revolusi social budaya,dan prilaku .

Urgensi pembiasaan membaca Al-Qur'an harus dihidupkan kembali karena . realitasnya dilapangan masih banyak mahasiswa perguruan tinggi umum, kemampuan baca Al-Quran sangat minim.Disinilah tujuan Urgensi pembinaan secara intensif ke pada mahasiswa agar mampu membaca Al-Qur'an dengan baik dan benar karena Al-qur'an sebagai sumber ilmu pengetahuan dan sebagai pedoman bagi manusia sebagai standar kehidupan manusia agar pola kehidupan terarah dengan petunjuk Al-Qur'an.Tujuan penelitian ini adalah sebagai konsekwensi mata kuliah pendidikan agama Islam di Universitas Buana perjuangan karawang sebagai sarana untuk membakali mahasiswa memiliki semangat menjadi generasi Qur'ani yang berakhlakul karimah sesuai petunjuk Al-qur'an.

Kata Kunci Urgensi,Pembinaan, Intensif, Target, revolusi industry 4.0.

\section{A.PENDAHULUAN}

Al-Quran sebagai sumber ilmu pengetahuan, Pendidikan Agama Islam di perguruan tinggi umum bertujuan untuk meningkatkan pemahaman, penghayatan dan pengamalan ajaran Islam secara komprehensif. Untuk mencapai tujuan Pendidikan Agama Islam tersebut perlu dilandasi dengan kemampuan membaca Al-Qura'an dikalangan mahasiswa. Ada beberapa kendala yang dihadapi oleh dosen Pendidikan Agama Islam di Perguruan Tinggi umum adalah latar belakang mahasiswa yang pada dasarnya berasal dari sekolah umum, sehingga beragam kemampuan dalam membaca Al-Qur'an. Kemajuan teknologi digital harus mampu memberikan perubahan yang lebih baik,sarana prasarana teknologi komunikasi semakin mudah. Kemudahan di era digital ini harus menjadi kontribusi terhadap kemajuan ilmu pengetahuan yan bersumber dari Al-Quran. Mahasiswa perguruan tinggi umum harus mampu mengembangkan potensi keimanan, ketaqwaan dan akhlak mahmudah dengan menjadikan AlQuran'an adalah sumber ilmu pengetahuan, sumber akhlak. Kemudahan di era revolusi 
Siti masruroh

Vol 3 No 2

ISSN : 2541-6995

E ISSN : $2580-5517$

industri 4.0 harus dimbangi dengan adanya keseimbangan( equalibi) pola kehidupan. Dijelaskan dalam Al-Qur'an surat Al Imran ayat 11 yang artinya" Barang siapa yang berpegang teguh di jalan Allah ,pasti di beri hidayah memalui jalan yang benar" ( Al-Imran:11)

Tujuan dari penelitian yang akan dicapai dari penelitian ini adalah menggali potensi kemampuan membaca Al-Qur'an mahasiswa di perguruan tinggi umum serta memberikan pembinaan secara intensif kepada mahasiswa yang belum mampu membaca Al-Quran, sebagai sarana membentengi generasi muda dari pengaruh negative revolusi industry dimana semua informasi mudah di akses dengan semakin canggihnya teknologi,yang banyak mempengaruhi tatanan kehidupan,karena penggunaan teknologi informasi yang mudah diakses maka akan mendistorsi kehidupan generasi muda/masyarakat.

\section{Metode Penelitian}

Analisis data dalam penelitian kualitatif dilakukan pada saat pengumpulan data berlangsung, dan setelah selesai pengumpulan data dalam periode tertentu. Pada saat wawancara, peneliti sudah melakukan analisis terhadap jawaban dari informan. Apabila jawaban yang diwawancarai setelah dianalisis terasa belum memuaskan, maka peneliti akan melanjutkan pertanyaan lagi, sampai tahap tertentu sehingga diperoleh data yang kredibel.

Secara umum, penelitian kualitatif dalam melakukan analisis data banyak menggunakan model analisis yang dicetuskan oleh Miles dan Huberman yang sering disebut dengan metode analisis data interaktif. Mereka mengungkapkan bahwa aktivitas dalam analisis data kualitatif dilakukan secara interaktif dan berlangsung secara terus-menerus sampai tuntas, sehingga datanya sudah jenuh. Aktivitas dalam analisis data kualitatif ada tiga, yaitu tahap reduksi data, display data, dan kesimpulan atau verifikasi. Uraian secara rinci metode yang digunakan meliputi tahapan-tahapan penelitian ,lokasi penelitian,pengamatan, dan observasi saat berlangsung pembelajaran pendidikan agama Islam di dalam kelas dengan model yang digunakan rancang penelitian dengan teknik pengumpulan dan analisis data dengan pengumpulan dan analisis informasi, serta penafsiran dan penarikan kesimpulan penelitian

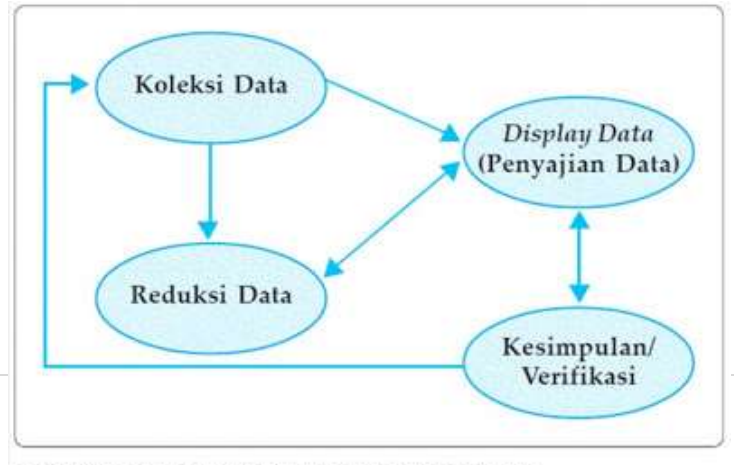


Siti masruroh

Vol 3 No 2

ISSN : 2541-6995

E ISSN : 2580-5517

\section{B. PEMBAHASAN}

\section{Pengertian Urgensi}

Pengertian Urgensi dalam kamus besar bahasa Indonesia urgensi bermakna /urgen-si/urgen keharusan yang mendesak, hal ini sangat penting untuk meningkatkan disiplin ${ }^{1}$

Pembinaan proses/cara /perbuatan, atau pembaharuan atau penyempurnaan.menurut para ahli pembiaan berarti suatu usaha ,tindakan dan kegiatan yang dilakukan secara berdaya guna berhasil guna untuk memperoleh hasil yang lebih baik. Secara umum pembinaan disebut sebagai sebuah perbaikan terhadap pola kehidupan yang direncanakan.Pembianaan dalam kamu besar bahasa Indonesia berasal dari kata bina dimulai dari awalan- pe dan akhiran -an berarti membina,memperbaharui atau proses,perbuatan, cara membina ,usaha,tindakan, dan kegiatan yang dilakukan secara berdaya guna berhasil guna untuk memperoleh hasil yang lebih baik ${ }^{2}$

\section{AL-Qur'an Menjawab Perubahan Revolusi Industri 4.0}

Al-Qur'an merupakan sumber ajaran Islam dan merupakan sumber informasi bagi umat manusia ,membina manusia untuk memudahakan manusia untuk mengetahui esensi kehidupan baik cara beribadah mauapun bermuamalah.Hal yang perlu dicermati dengan baik dari Al-Qur'an adalah menjadi pemandu hidup di antara kemajuan teknologi yang identik manusia hidup serba instan.

Definisi Al-Qur'an memiliki arti mengumpulkan dan meghimpun,dn qiroah yang berarti menghimpun hurup-hurup dan kata-kata satu dengan yang lain dalam satu ucapan yang tersususn rapih,Qur'an pada mulanya seperti qiroah, yaitu masdar (invinitif) dari kata qora',qirodatan, quranan, ${ }^{3}$ Allah berfirman dalam surat al Qiyamah ayat 17-18) .Artinya “ Sesungguhnya atas tanggungan Kamilah mengumpulkan dalam (dadamu) dan ( membuatmu pandai) membacanya, Apabila kami telah selesai mebacakannya maka ikutilah bacaanya9 Q;S;Al Qiyamah ayat 17-18)

2.2. Karakter masyarakat industry 4.0

\footnotetext{
${ }^{1}$ https://kkbi.web.id/urgensi

2 Departeman Pendidikan Nasional,Kamus Besar Bahasa Indonesia, (Jakarta Balai Pustaka,2003)h,123

${ }^{3}$ Manna Khalil al Qattan, Studi Ilmu-Ilmu Al-Qur'an,(lentera Antar Nusa 2002) h.15
} 
Siti masruroh

Vol 3 No 2

ISSN : 2541-6995

E ISSN : $2580-5517$

Industri 4.0 adalah nama terotomasi dan pertukaran data terkini dalam teknologi pabrik. Istilah ini mencakup sistem siber-fisik, internet untuk segala, komputasi awan, dan komputasi kognitif. ${ }^{4}$ Revolusi industri mengalami puncaknya saat ini dengan lahirnya teknologi digital yang berdampak massif terhadap pola hidup manusia diseluruh dunia. Revolusi industry kini atau disebut juga dengan generasi keemapat mendorong sistem otomasi di dalam proses aktifitas manusia. Teknologi internet semakin memudahkan akses informs dari seluruh dunia dengan menghubungkan jutaan manusia dalam memperoleh informasi.

Apapun aktifitas manusia dibantu dengan teknologi mulai dari pekerjaaan yang berat maupun pekerjaan yang ringan sekarang terkoneksi dengan teknologi untuk memudahkan pekerjaan manusia.Memudahkan terhubung dengan semua masyarakat tanpa batas yang ada diseluruh belahan dunia,dalam Al-Qur'an di jelaskan di surat al hujurat ayat 13

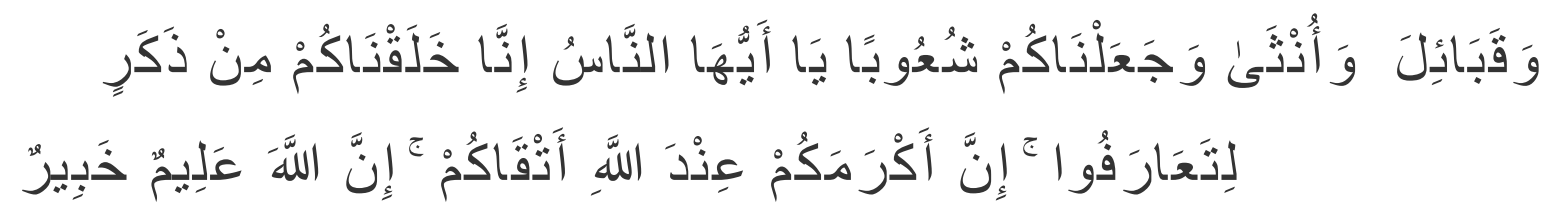

"Hai manusia, sesungguhnya Kami menciptakan kamu dari seorang laki-laki dan seorang perempuan dan menjadikan kamu berbangsa-bangsa dan bersuku-suku supaya kamu saling kenal-mengenal. Sesungguhnya orang yang paling mulia di antara kamu di sisi Allah ialah orang yang paling takwa diantara kamu. Sesungguhnya Allah Maha Mengetahui lagi Maha Mengenal". 5 Ayat ini menggambarkan tentang globalisasi dan mendorong manusia khususnya umat Islam harus mampu menghadapi percaturan global, harus dapat menangkap peluang dan menghadapi tantangan abad 21. Perubahan dan perkembangan berjalan terus begitu cepat dan kini telah muncul sebuah era revolusi

\footnotetext{
${ }^{4}$ https://id.wikipedia.org/wiki/Industri_4.0

ur.gen·si//urgénsi/ keharusan yang mendesak; hal sangat penting:meningkatkan disiplin .
} 
Siti masruroh

Vol 3 No 2

ISSN : 2541-6995

E ISSN : 2580-5517

industri 4.0. Bahkan banyak pula ayat-ayat al-Qur'an yang menyuruh manusia untuk meneliti dan memperhatikan alam semesta.

مدنون بـؤ لا قوم عن وال نذر بـ ت لات غ ني ومارض والات الـ سموا ف ي ذا ما ذظروا اق ل

Katakanlah: "Perhatikanlah apa yang ada di langit dan di bumi. Tidaklah bermanfaat tanda kekuasaan Allah dan rasul-rasul yang memberi peringatan bagi orang-orang yang tidak beriman. ”(QS Yunus : 101).Dengan penjelasanayat Al Qur'an ini ,maka harus

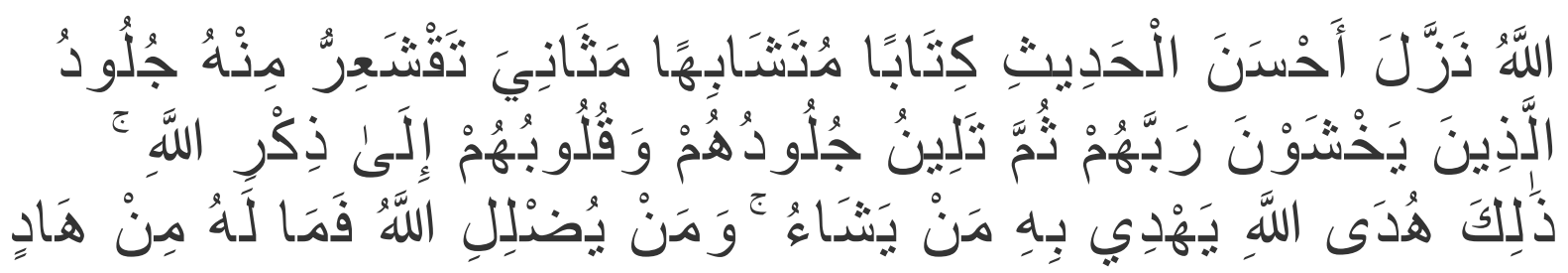

Artinya :"Allah telah menurunkan perkataan yang paling baik (yaitu) Al Quran yang serupa (mutu ayat-ayatnya) lagi berulang-ulang, gemetar karenanya kulit orang-orang yang takut kepada Tuhannya, kemudian menjadi tenang kulit dan hati mereka di waktu mengingat Allah. Itulah petunjuk Allah, dengan kitab itu Dia menunjuki siapa yang dikehendaki-Nya. Dan barangsiapa yang disesatkan Allah, niscaya tak ada baginya seorang pemimpinpun.”

Ketika kita bertanya mengapa harus membaca Al-Qur'an ? pasti akan menjawab karena membaca Al-Qur'an adalah amalan yang paling utama. Tapi dengan kemajuan teknologi informasi adanya pergeseran pemahaman tentang Al-Qur'an. Al-Qur'an dibaca hanya sebagai rutinitas yang dibaca ketika dibutuhkan utnuk acara seremonial,tanapa di aplikasikan dalam kehidupan. Urgensi membaca Al-Qur'an adalah memfokuskan pikiran dan prilaku serta tujuan hidup. Ketika kemajuan teknologi semakin maju, bukan berarti pemahaman dan penerapan AlQur'an semakin mundur. Tetapi Al-Qur'an merupakan refernsi kemajuan teknologi, karena muaranya ilmu adanya dalam Al-Qur'an.

Adapun target serta tujuan membanca Al-Qur'an di kalangan mahasiswa bukan semata hanya lancar membaca Al-Qur'an melainkan bagaimana mengaplikasikan ilmu dan teknologi dalam antara Al-Quran dan kemajuan teknologi yang saat ini, sudah berada direvolusi Industri 4.0.Ada beberapa target urgensi memebaca Al-Quran dikalangan mahasiswa muslim.

1. Al-Quran sebagai Sumber Ilmu Pengetahuan yang perlu dikembangkan

2. Al-Qur'an Menghidupkan hati,sebagaimana air menghidupkan tanah dan tumbuhan 
Siti masruroh

Vol 3 No 2

ISSN : 2541-6995

E ISSN : 2580-5517

3. Al-Qur'an sebagai sarana mendekatkan diri kepada yang menguasai kehidupan Allah Swt yang Maha Agung.

4. Al-Qur'an mendatangkan pehala dan balasan bagi orang yang hidupnya sibuk dengan Al-Qur'an

5. Al-Qur'an sebagai penyembuh penyakit fisik dan hati, karena salah satu fungsi alQuran adalah sebagai As syifa (obat)

6. Al-Qur'an mampu membedakan perbuatan terpuji dan tercela

Sesungguhnya kehidupan ini merupakan sebuah tantangan yang perlu dipesiapan dengan landasan yang kuat. Al Quran merupakan panduan kehidupan,apabila disebuah perusahaan tidak memeiliki panduan kerja yang jelas maka hasil kerja tersebut akan bermasalah. Begitupula apabila manusia memandang Al-Qur'an dengan senda guarau atau dianggap hal yang tidak pentingg maka tinggal menunggu kehancuran prilaku yang menyimpang dan jauh dari ajaran Al-Qur'an. Al-Quran menjawab segala persoalan yang sangat luar biasa, ketika kemajuan teknologi tidak bisa dibendung maka $\mathrm{Al}$ Qur'an akan menjawab dan mengatisipasi pengaruh negative dari kamjuan teknologi yang saat ini disebut dengan revolusi Induatri 4.0. Al-Qur'an sendiri menjawab gambaran hidup orang-orang sukses dalam menjawab persoalan hidup yang genting sekalipun. Seperti kisah Nabi Muhammad SAW beliau berkata kepada Abu Bakar Sidiq ketika terkurung di Gua Hira "Janganlah bersedih sesungguhnya Allah bersama kita."

adanya control disetiap aktifitas manusia karena sebagaimanapun teknologi itu canggih tetap bahwa kehidupan ini akan dipertanggungjawabkan di hadapan penguasa kehidupan Allah SWT.Dengan demikian maka akan timbul karakter sebagai seorang yang beriman yaitu memanfaatkan teknologi informasi sebagai wadah untuk mendekatkan diri pada Allah swt.

Penelitian yang sudah dilakukan peneliti yaitu tentang "Pembiasaan Membaca Al Qur'an dalam menanamkan karakter Siswa ( Studi Kasus di SMK Texar Kecamatan Klari Kabupaten Karawang). Terbit di Jurnal Pendidikan Islam Rabbani Universitas BUana Perjuangan Karawang. Menjelaskan tentang pementukan karakter siswa melalui pembiasaan membaca Al-Quran yang diselenggarakan sekolah satu minggu satu kali dalam acara Mabit (Malam bina Iman dan Taqwa smk Texar kec.Klari) 
Siti masruroh

Vol 3 No 2

ISSN : 2541-6995

E ISSN : 2580-5517

\section{KESIMPULAN}

Kesimpulan dan saran dari uaiaran diatas, perlunya perhatian yang serius dari pihak universitas untuk memfasilitasi berjalannya kegiatan pembinaan baca Al-Qur'an terhadap mahasiswa sehingga mampu menciptakan suasana kampus yang menjunjung tinggi nilainilai Al-Qur'an dalam nuansa akademik di Universitas Buana perjuangan Karawang khususnya bagi mahasiswa yang beragama Islam. Dengan terciptanya suasana akademik yang lebih religious walaupun perguruan tinggi umum yang menjunjung tinggi etika, agama dan moral. Mampu menemukan metode yang tepat untuk memberikan kesadaran dan pemahaman tentang pentingnya membaca, memahami dan mengamalkan isi kandungan Al-Qur'an.

\section{. Daftar Pustaka}

Badri Yatim,Dr,MA, Sejarah Peradaban Islam ,Dirosah islamiayah II. Jakarta, PT Raaja Grafindo Persada, 2008

Departemen Agama RI, Al-Quran dan Terjemah Alhikmah, Bandung, C.V Penerbit Diponegoro, 2014. Departemen Agama RI, Al-Quran dan Terjemah Alhikmah, Bandung, C.V Penerbit Diponegoro, 2014.

Departemen pendidikan dan kebudayaan. Kamus Besar Bahasa Indonesia, Cet. III, (Jakarta: Balai Pustaka, 1990),

Faisal Ismail, Studi Islam Kontemporer,perpustakaan Nasional, Cet I, 2018 https://id.wikipedia.org/wiki/Industri_4.0

Manna Khalil Al-Qattan, Studi Ilmu-Ilmu Al-Qur'an, Bogor, Litera Antra Nusa,2009

Sugiyono,2011. Metode Penelitian Pendidikan Pendekatan Kuantitatif,Kualitatif, Dan R\&D,Bandung,Alfabeta

Tim Aswaja NU center PWNU Jawa Timur, Khazanah Aswaja( Memahami,Mengamalkan dan mendakwahkan Ahlusunnah wal Jamaah),Pustaka Gerbang Lama,2016 